European Education, vol. 44, no. 1 (Spring 2012), pp. 71-92.

(C) 2012 M.E. Sharpe, Inc. All rights reserved. Permissions: www.copyright.com ISSN 1056-4934 (print)/1944-7086 (online)

DOI: 10.2753/EUE1056-4934440104

\title{
DUISHON SHAMATOV
}

\section{The Impact of Standardized Testing on University Entrance Issues in Kyrgyzstan}

In Kyrgyzstan, the breakup of the USSR raised many issues related to equity and fairness in education, one of which is the distribution of public funds to support scholarship admissions to higher education institutions. After 1992, public institutions could begin to charge tuition fees, but as a legacy of the USSR, Kyrgyzstan continues providing "budget-funded places" (public scholarships) for higher education study. In recent years, the number of these scholarships has been shrinking, resulting in increased competition for budget-funded places, and unfortunately, their distribution has been unfair and discriminatory against students from remote regions and poorer families. To address these issues, the merit-based National Scholarship Test (NST) was introduced in 2002 to identify the most deserving youth, irrespective of where they live and their backgrounds. Moreover, as a crucial part of the test implementation, quota categories have been introduced to ensure the proportional representation of youth from various geographic backgrounds at institutions of higher education. In the years since its introduction the NST has achieved both successes and setbacks. Generally considered a huge step forward, the NST has been able to impact equity in education on a broad scale. However, challenges still remain.

Duishon Shamatov is senior research fellow at the University of Central Asia (Bishkek). He conducts research on secondary and higher education, with expertise in teacher education, curriculum development, student assessment, and qualitative research. Address for correspondence: duishon.shamatov@ucentralasia.org. 
This article provides a review of the establishment of National Scholarship Testing in Kyrgyzstan. The new testing initiative has gone a long way toward promoting fair and merit-based access to budget-funded places of higher education in Kyrgyzstan. While the testing initiative has been successful to date, challenges to full institutionalization of the new testing and enrollment system remain. Employing a series of semistructured interviews and document analysis, this article describes the successes and challenges of the NST, with a focus on its impact on students' university entrance, and provides policy and program implications and recommendations.

Qualitative research methods allowed for a comprehensive and contextualized approach that took into account complex, multidimensional dynamics (Hitchcock \& Hughes, 1995; Merriam, 1998). This approach was particularly useful given the range of subjective opinions regarding standardized testing in Kyrgyzstan. The data were collected between April and August 2010 through document collection and analysis, individual and focus group interviews, and informal conversations. Electronic communication was also employed to obtain data from respondents.

Purposeful sampling was used to gain the maximum possible data from expert respondents about the independent testing organization (Merriam, 1998; Miles \& Huberman, 1994). Respondents to semistructured interviews included representatives of the Ministry of Education and Science (MoES) of Kyrgyzstan and the Kyrgyz Academy of Education (KAE), specialists from the independent testing organization-the Centre for Educational Testing and Teaching Methods (CEATM) - representatives of international donor agencies, local education experts working in international development organizations, professors from public and private universities, school administrators and teachers, community members, and students. In total, thirty people were interviewed. Before being interviewed, the respondents were informed of the purpose and nature of the study and their consent was obtained (Clandinin \& Connelly, 2000; Cohen \& Manion, 1997; Glesne, 1999). Among the expert respondents interviewed, and those identified herein, were Kamila Sharshekeeva (minister of education when the NST was established in Kyrgyzstan in 2002), John Clark (long-time advisor to K. Sharshekeeva), Akhunjan Abdrashev (state secretary of MoES), Asylbek Joodonbekov, specialist from the Kyrgyz Academy of Education, Todd W. Drummond (director of the National Testing Initiative), and Meerim Kadyrova (staff member of CEATM). 
Document analysis was another investigative tool utilized in the study (Bell, 1993). Materials, reports and other documents were reviewed and analyzed, including conference presentations, mass media materials, research reports, MoES documents and reports, CEATM reports, and materials and transcripts from the Central Asian Forum on University Admission and Development of Testing organized by CEATM in November 2009, as well as television programs of the Open Kyrgyzstan project of the Soros Foundation, Kyrgyzstan. ${ }^{1}$

\section{Kyrgyz education in the Soviet era}

The Soviets held that the pace of societal progress depended on the development of science and education, and Kyrgyzstan achieved considerable progress in education during the Soviet era (Holmes, Read, \& Voskresenskaya, 1995). From its outset, education in the USSR was free. With massive campaigns for basic education, the literacy rate in what is now Kyrgyzstan jumped from 16.5 percent in 1926 to 99.8 percent in 1979 (Ibraimov, 2001). Schools were built in the most remote mountain villages, and by 1978 there were 1,757 schools with 854,000 students and 50,000 teachers (Tabyshaliev, 1979). The legacy of Soviet school building projects clearly remains in Kyrgyzstan. As of 2009-10, according to Akhunjan Abdrashev (state secretary of MoES), there were 2,134 public schools, out of which there are 1,379 Kyrgyz-language schools, 162 Russian-language schools, 137 Uzbek-language schools, and 7 Tajiklanguage schools, as well as 449 schools that had two or more languages of instruction in 2009-2010 (personal communication, 8 July 2010).

Despite these remarkable advances, though, there were substantial problems with Soviet education. A system of education with both Kyrgyz- and Russian-language schools was introduced in Kyrgyzstan early in the Soviet era. Effectively, however, students were largely exposed to the same centrally designed curriculum, with only minor local adaptations (DeYoung, 2002; Heyneman, 2000). Though Soviet education espoused equality and uniformity, many scholars argue that, contrary to official doctrine, Soviet schooling was never really monolithic or egalitarian (Niyozov, 2001). The state controlled educational institutions, teaching appointments, syllabi, and textbooks to ensure that all learners were exposed to the same outlook and official knowledge and attitudes (Heyneman, 2000). While Soviet education overtly promoted internationalism above nationalist and ethnic identities, in practice it 
promoted Russian identity over other national identities within the USSR (Barrington, 2001; Korth, 2001; Laitin, 1998; Niyozov, 2001). After the late 1950s, parents ostensibly had a choice in the language of instruction for their children. However, socioeconomic and ideological pressure to send children to Russian-speaking schools was strong (Korth \& Schulter, 2003). Despite high learning standards and an ostensibly egalitarian approach, success in the Soviet Union was closely related to speaking and acting culturally Russian, resulting in a neglect of and even disdain for the titular or local languages of the various republics, as was the case with the Kyrgyz language, identity, and culture (Korth \& Schulter, 2003). As a result, many people, including elite Kyrgyz families, preferred Russian-language education, thus leading, over time, to the increased/ maintained quality of Russian-language schools and the subsequent deterioration/neglect of Kyrgyz-language schools. Additionally, besides clear disparities between Russian- and Kyrgyz-medium schools, obvious status differences also existed between urban and rural schools (Niyozov, 2001; Sutherland, 1999).

\section{Education in the post-Soviet era}

After the breakup of the Soviet Union, Kyrgyzstan began experiencing serious problems in the education sector (DeYoung, 2004). Almost 70 percent of Kyrgyzstan's population and 83 percent of schools are located in rural areas (UNDP, 2003). Children from rural and mountain schools receive poor-quality education. They are also frequently drawn away by agricultural work and other family responsibilities (DeYoung, Reeves, \& Valyaeva, 2006; Open Society Institute, 2002). According to official sources, over 2,500 school-age children dropped out of school in 2001, however, unofficial reports suggest that the actual number far exceeds this figure (DeYoung \& Santos, 2004). These dropout rates are a byproduct of economic collapse and declining support for the social sector, with primary reasons including poverty, insufficient nutrition, lack of adequate clothing, inability to afford learning materials, and the increasing cost of education. The declining prestige and perceived value of education has also contributed to dropout rates (Open Society Institute, 2002).

Attrition to education completion could be seen early on in the postSoviet era, with about 83.6 percent of the population of Kyrgyzstan completing secondary education in 1993 ; this decreased to 76.4 percent 
in 1996, and further to 69 percent in 1999 (DeYoung, 2002). In the past decade, preschool enrollment has declined catastrophically; out of 1,604 preschool institutions existing in 1991, only 416 remained by 2000 (DeYoung, 2004), and overall preschool enrollment in Central Asia was only 14 percent in 1999 (Open Society Institute, 2002). These significant declines in enrollment in preschool institutions are related to the increased costs of education, reduced state subsidies for transport and food, lower family incomes, but primarily due to closing of large number of preschool institutions. In fact, a very large number of preschool buildings were privatized, sold, and destroyed during the early years of independence.

The gap between the quality of education offered in urban and rural schools became evident in the decades since Kyrgyzstan gained independence. Under a reform effort called "diversification," new, innovative private schools such as lyceums, gymnasiums, and schools for gifted children emerged (Holmes, Read, \& Voskresenskaya, 1995; Open Society Institute, 2002). Overall, there are seventy-three private schools in Kyrgyzstan (A. Abdrashev, personal communication, 8 July 2010). These are mostly located in urban areas with wealthy families who can afford to pay school fees (Open Society Institute, 2002). In addition, many urban schools turned themselves into gymnasia or schools referred to as "new type" to generate extra income. "New-type" schools offer advanced coursework in addition to the national curriculum and extra academic services to students. They generally provide a better and more comprehensive education than "ordinary" state-funded schools and graduates have a better chance of entry to prestigious higher education institutions (A. Joodonbekov, specialist from the Kyrgyz Academy of Education, personal communication, 5 August 2010).

Higher education was free during the USSR and most students were eligible for state stipends. However, there were very few higher education institutions and only 15 percent of secondary school graduates were able to attend higher education institutions (DeYoung, 2008). After the breakup of the USSR, the number of higher education institutions increased from 10 to 50, with over 231,000 students enrolled-213,500 in public universities and 17,500 at private universities (Brunner \& Tillet, 2007). The percentage of secondary school graduates admitted to these higher education institutions is very high. In 2000-2, approximately 70 percent of school graduates were enrolled in higher education institutions. The number of students increased from 141 students per 10,000 
of the population in 1995 to 426 students per 10,000 in the $2004-5$ academic year (Brunner \& Tillet, 2007). This influx of higher education has not, however, been paired with a bustling job market. According to official and unofficial sources, every year anywhere between 50 and 80 percent of university graduates join the long list of unemployed youth in the country (ibid.).

While higher education was free during the former USSR, there were a small number of higher education institutions and only a small fraction of school graduates were actually able to enter universities. During the USSR and early years of independence, each higher education institution in Kyrgyzstan selected students for enrollment using its own entrance examination. There was no standardized entrance test across Kyrgyzstan. Each university conducted its own application and acceptance process and there were opportunities for corruption to thrive (A. Joodonbekov, personal communication, 5 August 2010).

Since independence, Kyrgyzstan's higher education sector adopted new educational financing policies that departed from the Soviet promise of a free education for all. The 1992 Law "On Education" allowed for paid educational services and public higher institutions began to charge tuition fees (Brunner \& Tillet, 2007). In addition to "budget-funded" or non-fee-paying students allocated on the basis of standardized testing, they also introduced "contract" or fee-paying students. ${ }^{3}$ In 1994 , 7.6 percent of students paid for their education, while in 2005,76 percent of university revenues were received from paid educational services and just 24 percent from the state budget. Thus, student fees now constitute a significantly higher proportion than public funds of higher education institution budgets. Even nominally "state" universities today only meet 10-15 percent of their budgetary requirements from state transfers and thus higher education institutions now compete with each other for students and are constantly trying to expand their enrollments (Reeves, 2003). In addition to the large number of institutions and their programs, there remain issues of quality control and program duplication by the various institutions.

\section{Establishment of national scholarship testing in Kyrgyzstan}

In the Soviet Union, existing entrance examinations, which included oral questions and writing pre-prepared essays, subjectively assessed factual 
knowledge and memorization skills and were affected by nepotism, favoritism, and a lack of transparency. In theory, university entrance was merit based, but exam results could be manipulated. Moreover, those who had connections or could offer bribes were in stronger positions to secure enrollment, than those from rural areas and poorer backgrounds. After the breakup of the USSR, each university continued conducting its own application and acceptance process and there were opportunities for corruption to thrive. Wealth and personal connections effectively replaced merit as essential prerequisites for enrollment at most universities with state scholarship funding. Meerim Kadyrova, test administration specialist of CEATM, described the situation as follows:

I was working at one of the universities in Bishkek. Those who had money and connections were able to get budget-funded places. The system was this way, and it was difficult to go against the stream. In 2001, I was on the admission committee. A disabled child with poor eyesight was taking the exam. He would get admission if he managed to get a satisfactory mark. But the chairperson ordered me to find fault with that child's documents by any means so that he was eliminated. (personal communication, 15 July 2010)

In 2002, the MoES called for major reform of the admissions process for higher education institutions and initiated national testing in Kyrgyzstan, thus creating the National Scholarship Test (NST) (see Drummond $\&$ DeYoung, 2004). This was done with the help of the American Councils for Collaboration in Education and Language Study (ACCELS) and the financial support of USAID (Drummond \& DeYoung, 2004). ${ }^{4}$ Prior to March 2004 there had been no independent testing agency, although ACCELS organized and conducted testing in 2002 and 2003. In 2004, the NST project created an independent testing organization, the Centre for Educational Assessment and Teaching Methods (CEATM), which took over the development and administration of the NST in Kyrgyzstan. ${ }^{5}$

When selecting the assessment instrument for the first NST in 2002, the MoES of Kyrgyzstan hoped to ensure equality of access to higher education and support for rural youth (K. Sharshekeeva, personal communication, 9 August 2010). The NST aimed to achieve objective, merit-based selection by testing the knowledge and skills of secondary school graduates applying for government scholarships. By reducing opportunities for corruption, this independently administered National Scholarship Test was seen as a more reliable tool of student assessment that would enable students from poorer areas to have a fair chance of 
securing budget-funded places at universities. Moreover, through the implementation of a quota system that mandates a proportional allotment of budget-funded scholarships in accordance with regional populations, the NST likewise sought to ensure equal access for those living in poor and rural reaches who are systematically disadvantaged in competition to quality education access. Currently, the Kyrgyz government allocates over 5,000 budget-funded places at public universities distributed on the basis of the applicants' NST scores. The government subsidizes 15,000 som (about \$321) for each budget-funded place to a university.

The National Scholarship Test replaced entrance examinations at the higher education institutions to a great extent. Almost all candidates who apply for state-funded budget-funded places take the NST. However, there has been regular reflections and consultations on the NST as an entrance examination for budget-funded places, and as of recently, candidates who apply to the some universities (Kyrgyz National Conservatory, National Art Academy, Kyrgyz State Art Institute, Kyrgyz State Construction, Transport, and Architecture University) and some specialized departments/fields, such as decorative art, physical training, and sport are not required to take the NST; they instead take internal examinations at universities. Ministry of Internal Affairs Academy and Bishkek Military School take into consideration NST results but they also conduct their internal exam. Since 2011, all students who apply to contract based education at universities are selected through their NST results.

Although not an explicit goal, it was hoped the NST would also drive overall educational reform in Kyrgyzstan. Teaching and learning in most secondary schools in Kyrgyzstan are oriented toward rote memorization rather than development of skills and competencies. The NST tests such competencies as critical thinking, problem solving, and the application of knowledge in real-life situations (CEATM report, 2010). By simply introducing these concepts in testing, it was hoped, perhaps unrealistically, that the NST would positively influence teaching and learning processes. The MoES believed that "new methods would become slowly institutionalized, and the challenge of finally motivating teachers to change their styles would be resolved" (Drummond \& DeYoung, 2004, p. 230).

\section{Grant distribution and quota categories}

In post-Soviet Kyrgyzstan, prior to the establishment of the NST, students at schools serving isolated and impoverished communities in villages and 
remote mountain areas rarely had opportunities to compete for budgetfunded places at universities. By introducing the NST, the MoES hoped to provide equality of access to higher education and support youth from rural contexts to compete for state-sponsored places. In 2003, to further ensure equal access to higher education, a quota system was introduced to ensure that state scholarships are distributed based on proportional representation from all regions of the country. According to Meerim Kadyrova, there were four quota categories prior to 2010: Bishkek schools, oblast center and town schools, village schools, and mountain area schools (personal communication, 15 July 2010).

In 2010, two more quota categories were added: bonus (privileged) and purposeful (target) categories. Bonus candidates are those who are physically disabled or suffered during the April 2010 events (when the former president Kurmanbek Bakiev was overthrown) and the KyrgyzUzbek ethnic violence of June $2010 .{ }^{6}$ Target candidates are those entering teaching specialties, due to an increasing shortage of teachers. Through special triparty agreements among universities, local village governments, and individual candidates, eight universities were identified to which target admission of applicants for teaching specialties was proposed. In this competition, applicants can apply for a budget-funded place, if they score above the passing NST grade, and have a "direction letter" from the district education department office ensuring a vacancy for a teaching position at a school. The same district education department is responsible for finding a job placement for the applicant on graduation.

Grant distribution with quota categories is the most critical component of the NST effort to make higher education more equitably accessible. Students scoring above the minimum mandatory cutoff NST score are eligible to compete in the scholarship competition. (In 2010, over 15,000 students could have participated in competitions for budget-funded and contract places.) Candidates from the same quota category compete with one another for places within the university department and specialty they desire and the highest scorers are awarded scholarships. Thus, the quota system ensures proportional representation of scholarship winners from the regions identified by the MoES (CEATM report, 2010). In addition to being eligible for grants, the NST examinees are also eligible for Golden Certificates, which are awarded to the fifty top-scoring students. A Golden Certificate allows a student to enter any budget-funded place at any public university of Kyrgyzstan without competition.

With the aim of objective and transparent selection of candidates on 
the basis of NST results, grant admission committees are formed that include the rector of each university, representatives of central and regional educational offices, and representatives from each university department, with a chair appointed by the university rector. The admissions committees choose among the applicants who have the highest score from each category and select the ones that fill in the allocated budget-funded places. However, the admission committees do not work transparently and may manipulate procedures. For example, committees may organize a second round of competition. In these instances some candidates may become unwary, leading them ultimately to withdraw and thus open up space for other, more favorable candidates. On a daily basis, the committee publicly displays the registered numbers and ranked scores according to each category. Candidates can regularly get information about the number of applicants, and their scores, ranking, and identification numbers. Furthering ensuring transparency, the MoES approves a list of independent observers who monitor the admission procedure. Observers are representatives of international and nongovernmental organizations, mass media, the president's office, and the prime minister's office. Independent observers are tasked to ensure transparency and cannot directly participate in the work of the grant admission committee, commit actions that may inhibit the work of the committee, or interfere in the admission decision-making process.

\section{The NST impact on equity}

Since its introduction, many young men and women in Kyrgyzstan have benefited from the NST. The test identifies strong students and, through its testing and quota system, increases access to higher education to the strongest candidates, regardless of geographic and social background (CEATM report, 2011). In so doing, it has corrected, to a certain extent, inequities of the past.

From 2002 to 2009, 217,061 graduates have taken the NST and over 39,000 were awarded state scholarships to study at higher education institutions in Kyrgyzstan (CEATM report, 2009). In 2009, 33,579 students took the NST and 4,928 were enrolled in budget-funded places at universities (see Table 1) (ibid.). These numbers represent grants that were awarded and accepted because some candidates may refuse to accept grants if they are not awarded those for the university or area of study in which they are interested. 
Table 1

Number of Students Who Took the NST and Won Grants in 2009

\begin{tabular}{|c|c|c|c|c|}
\hline \multirow[b]{2}{*}{ Quota categories } & \multicolumn{2}{|c|}{$\begin{array}{l}\text { Students who } \\
\text { took test }\end{array}$} & \multicolumn{2}{|c|}{$\begin{array}{l}\text { Students accepting } \\
\text { grant offers }\end{array}$} \\
\hline & No. & $\%$ & No. & $\%$ \\
\hline Village (rural) & 16,784 & 50.4 & 2,573 & 52.7 \\
\hline Mountain & 4,860 & 14.9 & 922 & 19.1 \\
\hline Oblast center and town & 5,064 & 15.5 & 689 & 14.3 \\
\hline Bishkek & 6,526 & 19.2 & 689 & 13.9 \\
\hline Total & \multicolumn{2}{|c|}{33,579} & \multicolumn{2}{|c|}{4,928} \\
\hline
\end{tabular}

Source: CEATM report, 2009.

Table 1 shows that a great majority of students who take NST and ultimately accept grants come from villages, in proportion with urban/ rural breakdown of students within the country. These results demonstrate that the NST is effective in terms of distributing university grants on more equitable terms. Students from Bishkek schools constituted 19.2 percent of the total number of students who took the NST, but only 13.9 percent of the Bishkek students accepted grants. This is most likely because students from urban schools often choose more prestigious specializations and turn down offered scholarships in specializations or universities that they do not want, opting instead for fee-paying education of their choice. There were very few scholarship places for popular majors such as English, law, economics, and computer science, and there is stiff competition for these places. ${ }^{7}$ Rural and mountain students usually enter the least prestigious specialties due to their relatively lower scores than grant winners from urban schools, and are more likely to accept scholarships for any specialization offered to them (Drummond, 2004). Choice for rural students is inevitably rather constrained unless they win scholarships, as only about 13 percent of places in public institutions are available to scholarship students, while 87 percent are obliged to pay fees.

By 2009, students around the country, particularly those from rural areas, started believing that with the NST their knowledge is being assessed fairly and they have opportunities to compete for grants regardless of their school history, origin, and social status. In 2009, over 70 percent of grant recipients were from rural and mountain schools. Table 2 shows the 
Table 2

Percentage of Enrolled Students from Rural Schools, 2002-8

\begin{tabular}{lccc} 
& $\begin{array}{c}\text { No. of NST } \\
\text { participants }\end{array}$ & $\begin{array}{c}\text { No. of enrolled students } \\
\text { in grant places }\end{array}$ & $\begin{array}{c}\text { \% of enrolled students } \\
\text { from rural students }\end{array}$ \\
\hline 2002 & 13,837 & 5,000 & 66.0 \\
2003 & 35,247 & 5,000 & 63.9 \\
2004 & 39,286 & 5,310 & 61.5 \\
2005 & 32,852 & 5,380 & 61.8 \\
2006 & 33,336 & 5,085 & 69.0 \\
2007 & 34,225 & 4,787 & 70.8 \\
2008 & 33,431 & 4,933 & 69.7 \\
Total & 222,214 & 35,495 &
\end{tabular}

Source: Centre for Educational Assessment and Teaching Methods (www.testing.kg/ en/).

percentages of rural students who accepted grants from 2002 to 2008.

Thus, the NST gained a good reputation among these students and their parents. As expressed by Mars Aliev, a student who was awarded a grant and now is a student of Kyrgyz-Turkish Manas University:

Free higher education became a real possibility for gifted, knowledgeable school graduates. The old system that served only the rich and high officials is over. Nowadays, the task of the school is not only to award a diploma by any means, but to prepare a student who can demonstrate by action the efforts and hard work of his teachers during entrance procedures to higher education institutions, thus raising the prestige of his school. Universities, in their turn, due to the National Scholarship Testing, received prospective specialists with human and intellectual potential in whom the state can and should invest. Our motherland gained a reputation in the international arena as a country that is taking care of its tomorrow. (As quoted in the CEATM report, 2008, p.11)

The results of the NST show that rural students have benefitted from the new system. However, the quality of each grant place is different because the specialties and universities vary in prestige. Thus, even though Bishkek students receive budget awards in a ratio approximating their representation in the overall population, grant-winning Bishkek students are represented in greater proportions in some urban (and hence elite) universities. This is because the number of budget-funded places assigned 
for each quota category is determined by the overall number of students who actually apply to a given faculty. As noted above, students from each quota category compete only against students from that category. However, there can be an effect on award distributions across categories based on the rates of student application from a particular quota group for a particular faculty: If no one from a quota group applies, there will be no budget-funded place awarded for that group.

For example, approximately half the budget-funded students enrolled in the Kyrgyz Russian Slavonic University (KRSU) in 2010 came from Bishkek and half from rural areas (CEATM report, 2010). This ratio for the Bishkek quota category is clearly higher than their overall proportion of applicants in the general population. This is most likely due to the fact that it is easier for Bishkek students to apply to KRSU than it is for rural students, as the former have no travel burden. There is also a popular perception that it is an "elite" institution, which might discourage less-informed applicants. At the same time, few urban students seek admissions in rural (generally less prestigious universities), which means that in many such institutions almost all the budget-funded places are allocated to students from those regions. (For more on the breakdown of rural and urban students entering faculties in each institution see the CEATM reports for 2007-11).

\section{Variables affecting NST impact}

Ironically, while more equitable access to higher education has been achieved, the results of the NST confirm that there are disparities in outcomes according to geographic location, medium of instruction, and the resources and teaching methods used in schools. Students from Bishkek schools score highest, followed by students from oblast center and town schools, followed by those at village schools, and finally by those from mountain schools. In 2007, reflecting results from previous years, students from Bishkek had an average score of 135.5, while students from oblast center and town schools scored 121.4, village students scored 107.0, and students from mountain schools scored the lowest, 106.3 (CEATM report, 2007). There was also a clear disparity of high performance corresponding to oblasts. Table 3 shows the number of those who scored 200 and higher in NST in 2009, according to location.

The highest-performing students compete to enter the specialties they desire and have better chances of getting awarded grants. The majority of 
Table 3 2009 NST Scores over 200 According to Oblasts and Large Cities in
Bishkek and Osh

\begin{tabular}{lrrrrrr} 
Location & 200 & 210 & 220 & 230 & 240 & 245 \\
\hline Chui oblast & 67 & 30 & 17 & 7 & 2 & \\
Yssyk-Kol oblast & 41 & 23 & 9 & 6 & & \\
Osh oblast & 33 & 9 & 1 & 2 & & \\
Talas oblast & 22 & 1 & 2 & 1 & & \\
Jalal-Abad oblast & 10 & 7 & 2 & & & \\
Batken oblast & 8 & 3 & 3 & & & \\
Naryn oblast & 7 & 2 & & & & \\
Bishkek city & 257 & 200 & 123 & 45 & 9 & 1 \\
Osh town & 29 & 8 & 1 & 2 & & \\
Kyrgyzstan & 445 & 275 & 158 & 61 & 11 & 1 \\
Source: CEATM report, 2009. & & & & & & \\
\hline
\end{tabular}

these high-performing students are from Bishkek and Chui oblast (located near the center and has more industrial towns), followed by Yssyk-Kol and Osh oblasts. The lowest numbers of high-performing students come from more remote oblasts: Naryn, Jalal-Abad, and Batken.

Historically, Russian-medium schools, most located in Bishkek, enjoyed privileged status in the country, and elite families still prefer to send their children to them. While efforts have been made to further develop Kyrgyz-medium schools since independence, economic difficulties and lack of effective policies and practices have hampered this process. The majority of Kyrgyz-medium schools are in rural and poor regions of the country, further exacerbating their disadvantage. Reflecting this, since the inception of the NST, students who take the test in Russian usually score highest (with an average of 133.2), followed by those taking the test in Kyrgyz (104.4), and then in Uzbek (100.6). It has also been found that if parents are more educated, their children tend to perform better in the NST (A. Joodonbekov, personal communication, 5 August 2010; M. Kadyrova, personal communication, 15 July 2010). As a rule, urban parents have higher education levels than rural parents.

Moreover, top NST performers are usually from private schools, such as Kyrgyz-Turkish schools or elite urban schools. These schools offer better-quality schooling, are well resourced, and their teachers are familiar 
with different teaching methodologies and international testing methods, whereas rural and mountain schoolteachers are not. Most of the latter group lack professional development opportunities to learn innovative teaching approaches, and, as a result, focus on textbook coverage and memorization rather than critical thinking and application of knowledge. In many cases, textbooks are the only tools that teachers have and they follow them strictly in their practices (A. Joodonbekov, personal communication, 5 August 2010).

Finally, it is also true that Golden Certificate winners usually come from private schools or elite Bishkek gymnasia (Benliyan, 2009). In 2009, graduates from one gymnasium in Bishkek received eighteen out of the fifty available Golden Certificates. Thus, the certificates simply seem to reinforce the fact that while NST addressed some issues related to equity in access to higher education, equity in quality of education remains an issue. Beyond what can be accomplished by the NST, the government should be taking more proactive measures to improve quality of all schools by using the lessons from the NST scores. Without such measures, the gap and stratification will further increase, with only a small fraction of students, those in big cities, getting the best education.

Testing is a learned skill. Students from Kyrgyz-Turkish schools and other elite schools sit for tests in their subjects almost every week. In contrast to these students, most students from public schools and especially students from rural areas do not take tests in their classes and thus are not familiar with test-taking skills and strategies. A rural schoolteacher interviewed observed, "Most of our students get anxious when they sit in test halls in the district center. This is due to their poor self-esteem. Our students normally do not have this kind of experience in their whole life at school." Often, rural teachers are not equipped to design and conduct tests. CEATM has a Web site with resources for teachers to guide them in their preparation of students for NST and assist them in teaching differently. However, only a small fraction of secondary school teachers, mostly from Bishkek and other urban centers, have access to the Internet.

The disparity in test scores by language and demographics, and resources raises serious questions for educators and policymakers in Kyrgyzstan. Urban schools usually have better resources, can afford to invest more in their students, and are better prepared for the type of skills that the NST measures. Teaching and learning in rural and mountain schools remains oriented toward rote memorization and recall of facts rather than skills development or attaining educational outcomes. 


\section{Challenges for the NST}

During the initial years, some local education authorities at the district level used NST results to assess and compare school quality. In 2003 and 2004, education authorities punished schools whose students performed poorly, instead of analyzing test results and providing the necessary support. As a CEATM specialist commented, "Some district education officials prepared their ranking tables for the schools in their districts and used those schemes to reward and punish, and this is against the principles of the NST." Given the disparity between what many schools taught and the skills and knowledge that the NST measured, this put these schools in an unfair position. Many local education officials and school administrators were admonished and even fired if their NST results were poor. As a result, there is pressure for school administrators to choose which students take tests so that the average score of the school goes up (M. Kadyrova, personal communication, 15 July 2010). Thus, many teachers started focusing on test preparation rather than improving skills and knowledge. As Asylbek Joodonbekov from the Kyrgyz Academy of Education said, "It is a pity that there are cases where our schoolteachers use a lot of their class time for test preparation" (personal communication, 5 August 2010). Teachers changed class formats and devoted large amounts of class time to test preparation, rather than comprehensive teaching, to avoid political and administrative pressure.

Among the NST's most profound effects and challenges, many students have started taking private tutoring to learn the skills tested in the NST. Parents have started hiring university professors or other specialists to offer private tutoring to their children. A parent from Osh interviewed noted:

My elder son is a graduate of secondary school in this year. He also participated in the NST test. Now we are waiting for the test results. My son prepared for the NST test for almost one year. He attended additional classes. We paid for his private university tutors so he could learn important skills that are tested in the NST, since schoolteachers cannot teach their students at the level they need to get a good score.

Payment for tutoring is different depending on tutors' competencies and location of schools; there are not many well-prepared tutors in rural and mountain areas and not every parent can afford to pay for additional classes in rural locales. The interviews revealed that rural students normally pay from 100-300 som per hour of tutoring, while urban students 
pay up to $1,000 \mathrm{som}$. Private tutors are either university teachers or schoolteachers who have experience with standardized tests.

Many secondary school students undergo tutoring; this indicates many problems: there is a disconnect between what is taught in many schools and what is tested in the NST; teachers' inability to teach necessary testing skills and knowledge; parents' distrust of the level of teaching in schools; and continued inequity within the education system because not everyone can afford high-quality private tutoring (Silova, 2009). It is true that private tutoring is not a new problem for examination preparation, and was present even in during the Soviet period. However, the intensity of test preparation for NST is higher and the social stratification gap in Kyrgyzstan is increasing.

\section{Conclusions and implications}

The NST has had a positive impact on the distribution of grants and budget places in universities across Kyrgyzstan. This is particularly true in rural and remote mountain areas where students can now access previously inaccessible grants and budget-funded spaces at universities. However, some key issues have emerged or been highlighted in the nine years since the NST was introduced.

One issue is related to the fact that the higher-quality universities are mostly located in Bishkek (DeYoung, 2011). Currently, many village students apply to regional universities simply because living in Bishkek is expensive. It is necessary to take proactive measures to help rural students attend urban universities; otherwise, stratification will increase. If a quota system helps students from rural areas enter the best universities in Bishkek, it is necessary to ensure that they will succeed and maintain that institution's standards. Universities need to offer additional courses to support these students, and grants should include not only tuition fees but also accommodation and transportation expenses. In the long term, it is also imperative to work on strengthening regional universities. Also, while the NST grant distribution system was designed to be transparent, some challenges remain. As stated earlier, the Golden Certificates are not awarded on the quota system, and winners usually come from selected private schools or elite Bishkek gymnasia. Perhaps the Golden Certificates could be awarded according to a quota category to ensure more equity within the system.

One of the unintentional negative consequences of the introduction 
of the NST has been the rise of private tutoring to prepare students to take the test, continuing inequity within the education system (Silova, 2009). Those who can afford the best tutoring are likely to do better. If any individual is being deprived of equal opportunities to compete for state scholarships due to financial constraints, government officials should address this issue. The education officials in Kyrgyzstan need to do systematic analysis and develop necessary safety nets to avoid anticipated or unanticipated fallout based on testing.

It is also imperative that a national curriculum should be improved to upgrade the quality of education at all schools. The NST has the potential to significantly influence broader education reforms in Kyrgyzstan, such as setting internationally competitive national standards and benchmarks, motivating curriculum and textbook development, teacher training, and effective assessment. At the moment, the NST continues testing skills, which the author views as necessary, that are not taught in most Kyrgyz schools-for example, critical thinking, problem solving, and application of knowledge in a real-life situation. The NST has drawn attention to certain deficits in Kyrgyzstan's national curriculum. As the competencies tested on the NST are considered vital, it is imperative that proactive attempts are made to promote the same competencies in curricula at all schools, particularly in village and mountain schools. Teaching and learning must be conscientiously improved in those schools, and imbalances in educational resources must be corrected.

There are many longstanding inequities in the education system in Kyrgyzstan. Disparities in NST scores based on language, demographics, and resources raise serious questions for educators and policymakers. The NST results could be used more effectively in highlighting and addressing these disparities. Purposeful measures are needed to help rural students attend urban universities; otherwise, the stratification gap will increase. Overall, there is a shortage of solid and systematic research on aptitude tests and their implications for equity and quality issues in a society such as Kyrgyzstan, which is experiencing dramatic changes while witnessing the decline of education quality.

Eventually, it may be necessary to eliminate budget-funded places at universities. The budget system could be replaced by university-based discounts in fee payments to students based on their performance, while the government could then allocate funds for needs-based scholarship only. This needs-based scholarship could include not only university fees, but also accommodation, books, and other expenses that allow 
promising applicants to apply and study at any university irrespective of where they are from.

In conclusion, most of the issues raised by the creation, implementation, and direct and indirect outcomes of the NST are related to broader educational and economic issues in Kyrgyzstan. The NST has shown that through a coordinated national effort, it is possible to improve access to higher education. However, the NST has also highlighted existing weaknesses within the education system and provides opportunities to better understand and address those weaknesses. There is a need for more consolidated collaboration and joint work among stakeholders who work on education standards, curriculum development, textbook publication, teacher training and retraining, assessment, and evaluation. International organizations involved on education reforms and social development in Kyrgyzstan, under the monitoring and coordination of the MoES should work collaboratively to avoid unnecessary duplication and unsustainability (Benliyan, 2008). Systemic change in education is possible when all stakeholders and international organizations coordinate their activities.

\section{Acknowledgment}

I would like to express my gratitude to Sia Nowrojee for her editorial assistance on the paper.

\section{Notes}

1. The Central Asian Forum titled "University Admission and Development of Testing" was organized on 5-6 November 2009 by CEATM (see www.testing.kg for details). The forum was attended by representatives of MoES of Kyrgyzstan, Kazakhstan, the Russian Federation, Tajikistan, Kyrgyz government representatives, and specialists from international and nongovernmental organizations, universities, departments of education, schools, and the business community. A televised discussion, "National Scholarship Testing or Unified State Examination: What Is the Difference?" was the Project of Open Kyrgyzstan of the Soros Foundation, Kyrgyzstan held 16 April 2009. www.open.kg/ru/theme/?theme_id=97.

2. To be classified a "new type," a school has to have highly qualified, innovative teachers and sufficient facilities and resources, including textbooks and a library. These schools got even better by departing from government regulations of compulsory curriculum and schooling policies, and in many cases attracting money from the international development agencies.

3. Higher education institutions themselves can determine the number of paying (contract) students but it has to be approved by the MoES. Tuition fees of higher education institutions vary. Some universities charge low tuition to attract students 
as an additional source of revenue, but in 2009 the MoES established a base fee threshold of 15,000 Kyrgyz som per year for day students and 13,000 Kyrgyz som for part-time students in public institutions. Tuition fees in private universities are nearly 25 percent higher than in public ones, but some of the more prestigious institutions charge higher fees; for example, the American University charges about 80,000 som.

4. The introduction of NST is associated with Kamila Sharshekeeva, minister of education in 2002 (DeYoung, 2004). She initiated the reform in the admission procedures of higher education institutions as she was dissatisfied with the quality of examinations and the corruption in university admission procedures. As Todd Drummond commented, "It was Kamila Sharshekeeva who was vital in this reform. She was able to work together with the president. Thus, this reform was successful!" (personal communication, 9 August 2010). John Clark believes that the NST reform was ultimately a success because then-president Askar Akaev was willing to introduce changes to all spheres including education (personal communication, 10 May 2010). In 2002, Akaev issued a decree initiating the first NST.

5. Benjamin Bloom, an American educational psychologist, made contributions to the classifications of educational objectives. In Kyrgyzstan, Bloom's theories, especially his taxonomy of learning objectives have become increasingly popular since the breakup of the USSR, being introduced by different international development agencies including the Soros Foundation.

6. Under the decree of the Interim Government of Kyrgyzstan from 10 June 2010 on distribution of grant places based on NST scores, a special State Grant Committee was formed under the MoES. In total, 140 grant places are planned for the children of those who suffered in the events of the spring and summer of 2010.

7. Every year, the government of Kyrgyzstan allocates budget places based on the state-identified needs of the country for different specialities. These days, priority is given to pedagogical specialties as more than half of budget grants are for "future teachers." Unfortunately, because of low salaries and limited future opportunities, the teaching profession is in less demand and therefore those students who can afford to pay tuition fees refuse state grants and choose professions other than teaching. Most students who pay from their own pocket, study management, economics, law and humanitarian sciences, and generally prefer to be enrolled in private universities. Children from low-income families have fewer opportunities to enter higher education institutions because of the poor quality of secondary education they receive. For more detailed analysis of low-scoring students in NST and how a majority of them are able to enter preservice teacher education specialities due to their low scores, refer to Silova (2009).

\section{References}

Barrington, L. (2001). Russian-speakers in Ukraine and Kazakhstan: "Nationality," "population," or neither? Post-Soviet Affairs, 17(2), 129-158.

Bell, J. (1993). Doing your research project. Buckingham: Oxford University Press.

Benliyan, A. (10 July 2009). Luchshiy ball Evgenii [Evgenia's highest score]. Vechernyi Bishkek, 127 (9795).

Brunner, J., \& Tillet, A. (Eds.). (2007). Higher education in Central Asia: The 
challenges of modernization (case studies from Kazakhstan, Tajikistan, the Kyrgyz Republic and Uzbekistan). New York: International Bank for Reconstruction and Development/World Bank.

CEATM report [Center for Educational Assessment and teaching Methods]. (2007). Results of NST and enrollment in grant places of higher education institutions of the Kyrgyz Republic in 2007. www.testing.kg/files/pdf/reportR2007.pdf. . (2008). Results of NST and enrollment in grant places of higher education institutions of the Kyrgyz Republic in 2008. www.testing.kg/files/pdf/ reportR2008.pdf.

. (2009). Results of NST and enrollment in grant places of higher education institutions of the Kyrgyz Republic in 2009. www.testing.kg/files/pdf/ reportR2009.pdf.

. (2010). Results of NST and enrollment in grant and contract-based places of higher education institutions of the Kyrgyz Republic in 2010. www. testing.kg/files/pdf/2010/reportR2010.pdf.

- (2011). Results of NST and enrollment in grant and contract-based places of higher education institutions of the Kyrgyz Republic in 2011. www. testing.kg/files/pdf/2011/reportR2011.pdf.

Clandinin, D.J., \& Connelly, F.M. (2000). Narrative inquiry: Experience and story in qualitative research. San Francisco: Jossey-Bass.

Cohen, L., \& Manion, L. (1997). Research methods in education. (4th ed.). London: Routledge.

DeYoung, A. (2002). West meets East in Central Asia: competing discourses on education reform in the Kyrgyz republic. Journal of Educational Research, Policy and Practice, 3(3), 3-45.

- (2004). On the current demise of the "Action Plan" for Kyrgyz education reform: A case study. In S.P. Heyneman \& A. DeYoung (Eds.), The challenges of education in Central Asia (pp. 199-224). Greenwich, CT: Information Age.

- (2008). Conceptualizing paradoxes of post-socialist education in Kyrgyzstan. Nationalities Papers, 36(4), 641-657.

- (2011). Lost in transition: Redefining students and universities in the contemporary Kyrgyz Republic. Greenwich, CT: Information Age.

DeYoung, A., \& Santos, C. (2004). Central Asian educational issues and problems. In S.P. Heyneman \& A. DeYoung (Eds.), The challenges of education in Central Asia (pp. 65-80). Greenwich, CT: Information Age.

DeYoung, A., Reeves, M., \& Valyaeva, G. (2006). Surviving the transition? Case studies of schools and schooling in the Kyrgyz Republic since independence. Greenwich, CT: Information Age.

Drummond, T. (2004). The national testing initiative of the Kyrgyz Republic, 2003: Test results, accomplishments and prospects for sustainability. Paper presented at the CESS 5th annual conference. Indiana University, Bloomington, IN, 15 October, 2004.

Drummond, T., \& DeYoung, A. (2004). Perspectives and problems in education reform in Kyrgyzstan: A case of national scholarship testing. In S.P. Heyneman \& A. DeYoung (Eds.), The challenges of education in Central Asia (pp. 225-242). Greenwich, Connecticut: Information Age.

Glesne, C. (1999). Becoming qualitative researchers: An introduction (2d ed.). New York: Longman. 
Heyneman, S. (2000). From the party/state to multiethnic democracy: Education and social cohesion in Europe and Central Asia. Educational Evaluation and Policy Analysis, 22(2), 173-191.

Hitchcock, G., \& Hughes, D. (1995). Research and the teacher: A qualitative introduction to school-based research. London: Routledge.

Holmes, B., Read, G.H., \& Voskresenskaya, N. (1995). Russian education: Tradition and transition. New York: Garland.

Ibraimov, O. (Ed.). (2001). Kyrgyzstan: Encyclopedia. Bishkek: Center of National Language and Encyclopedia.

Korth, B. (2001). Bilingual education in Kyrgyzstan: Pros and cons. In Bilingual education and conflict prevention. Conference proceedings (pp. 141-150). Bishkek: CIMERA.

Korth, B., \& Schulter, B. (2003). Multilingual education for increased interethnic understanding in Kyrgyzstan. Bishkek: CIMERA.

Laitin, D. (1998). Identity in formation: The Russian-speaking populations in the near abroad. Ithaca, NY: Cornell University Press.

Merriam, S. (1998). Qualitative research and case study applications in education. San Francisco: Jossey Bass.

Miles, M., \& Huberman, M. (1994). Qualitative data analysis: An expanded sourcebook. Thousand Oaks: Sage.

Niyozov, S. (2001). Understanding teaching in post-Soviet, rural, mountainous Tajikistan: Case studies of teachers' life and work. Unpublished Ph.D. dissertation, University of Toronto.

Open Society Institute: Education Support Program. (2002). Education development in Kyrgyzstan, Tajikistan and Uzbekistan: Challenges and ways forward. www.osi-edu.net/esp/events/materials/final.doc.

Reeves, M. (2003). Markets, “missions” and languages of higher education reform in Kyrgyzstan. Paper Presented to the CESS th Annual Conference. Cambridge, MA, 4 October 2003.

Silova, I. (Ed.). (2009). Private supplementary tutoring in Central Asia: New opportunities and burdens. Paris: UNESCO and IIEP.

Sutherland, J. (1999). Schooling in the new Russia: Innovation and change, 1984-1995. London: Macmillan/St. Martin's Press.

Tabyshaliev, S. (Ed.). (1979). Torzhestvo idei velikogo oktiabria v Kirgizii [Trimuph of the Octoberists' ideas in Kyrgyztan]. Frunze: Ilim.

UNDP Report. (2003). The Kyrgyz Republic. Millennium development goals: Progress report. Bishkek: UNDP. www.undp.kg/english/publications/2003/ mdgpr2003.pdf. 
Copyright of European Education is the property of M.E. Sharpe Inc. and its content may not be copied or emailed to multiple sites or posted to a listserv without the copyright holder's express written permission. However, users may print, download, or email articles for individual use. 